\title{
GENERALISED SEMI CLOSED SETS IN GRILL TOPOLOGICAL SPACES
}

\section{S. Vibin Salim Raj ${ }^{1 *}$, V. Senthil kumaran ${ }^{2}$, Y. Palaniappan ${ }^{3}$}

*1 M. Phil, Scholar, Arignar Anna Government Arts College, Musiri, Tamilnadu, India Email: rajvibin10@ gmail.com ${ }^{2}$ Associate Professor of Mathematics, Arignar Anna Government Arts College, Musiri, Tamilnadu, India. Email: vsenthil1966@gmail.com

${ }^{3}$ Associate Professor of Mathematics (Retd.), Arignar Anna Government Arts College, Musiri, Tamilnadu, India Email: palaniappany48@gmail.com

Corresponding Author: -

Email:rajvibin10@gmail.com

\begin{abstract}
: -
The purpose of this paper is to introduce and investigate a new class of generalized semi closed sets in terms of Grill $G$ on X. The characterization of such sets along with certain other properties of them are obtained.
\end{abstract}

Keywords: $g$ s closed, topology $\tau_{\mathrm{G}, \text { operator }} \phi, G_{(g) *} *$ closed. 2010 AMS subject classification: 54 B05, $54 C 05$ 


\section{INTRODUCTION}

It is found from literature that during recent years many topologists are interested in the study of generalized types of closed sets. For instance, a certain form of generalized closed sets was initiated by Levine [6] whereas the notion of generalized *semi closed ( $\mathrm{g} * \mathrm{~s}$ closed) set was studied by Veerakumar [9]. Following the trend, we have introduced and investigated a kind of generalized closed sets, the definition being formulated in terms of grills. The concept of grill was introduced by Choquet [1] in the year 1947. From subsequent investigations it is revealed that grills can be used as an extremely useful device for investigation of a number of topological problems.

\section{PRELIMINARIES}

Definition 2.1: A nonempty collection $G$ of non-empty subsets of a topological space $\mathrm{X}$ is called a

(i) $\mathrm{A} \in \mathrm{G}$ and $\mathrm{A} \subseteq \mathrm{B} \subseteq \mathrm{X} \Rightarrow \mathrm{B} \in \mathrm{G}$ and

(ii) $A, B \subseteq X$ and $A \cup B \in G \Rightarrow A \in G$ or $B \in G$

Let $\mathrm{G}$ be a grill on a topological space $(X, \tau)$. In [7] an operator $\phi: \mathrm{P}(\mathrm{X}) \rightarrow \mathrm{P}(\mathrm{X})$ was defined by $\phi(\mathrm{A})=\{\mathrm{x} \in \mathrm{X} / \mathrm{U} \cap \mathrm{A} \in \mathrm{G}, \forall \mathrm{U} \in \tau(\mathrm{x})\}, \tau(\mathrm{x})$ denotes the neighborhood of $\mathrm{x}$. Also the map $\psi: \mathrm{P}(\mathrm{x}) \rightarrow \mathrm{P}(\mathrm{x})$, given

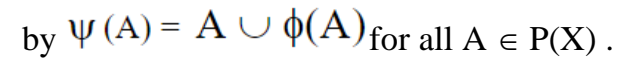

Corresponding to a grill $\mathrm{G}$, on a topological space $(X, \tau)$ there exists a unique topology $\tau_{\mathrm{G}}$ on $\mathrm{X}$ given by $\tau_{\mathrm{G}}=\{\mathrm{U} \subseteq \mathrm{X} / \psi(\mathrm{X} \backslash \mathrm{U})=\mathrm{X} \backslash \mathrm{U}\}_{\text {where for any }} \mathrm{A} \subseteq \mathrm{X}, \psi(\mathrm{A})=\mathrm{A} \cup \phi(\mathrm{A})=\tau_{\mathrm{G}}-\mathrm{cl}(\mathrm{A})$.

Thus a subset $\mathrm{A}$ of $\mathrm{X}$ is $\tau_{\mathrm{G}}$-closed (resp. $\tau_{\mathrm{G}}$-dense in itself) if $\psi(\mathrm{A})=\mathrm{A}$ or equivalently if $\phi(\mathrm{A}) \subseteq \mathrm{A}$ (resp. $\mathrm{A} \subseteq \phi(\mathrm{A}))$

In the next section, we introduce and analyse a new class of generalized closed sets, namely $\mathrm{G}(\mathrm{gs}) *$ closed sets, in terms of a given grill $\mathrm{G}$, the definition having a close bearing to the above operator $\phi$.

We introduce and investigate the notion of $(\mathrm{gs})^{*}$ continuous functions in grill topological spaces. Also, we investigate the relationship with other functions.

Throughout the paper, by a space $X$ we always mean a topological space $(X, \tau)$ with no separation properties assumed. If $A \subseteq X$, we shall adopt the usual notations int $(A)$ and $c(A)$ respectively for the interior and closure of $A$ in $(X, \tau)$. Again $\tau_{\mathrm{G}}-\mathrm{Cl}(\mathrm{A})$ and $\tau_{\mathrm{G}}-\operatorname{int}(\mathrm{A})$ will respectively denote the closure and interior of $\mathrm{A}$ in $\left(\mathrm{X}, \tau_{\mathrm{G}}\right)$. Similarly, whenever we say that a subset $A$ of a space $X$ is open (or closed) it will mean that $A$ is open (or closed) in (X, $\tau$ ). For open and closed sets with respect to any other topology on $\mathrm{X}$, eg. $\tau_{\mathrm{G}}$, we shall write $\tau_{\mathrm{G}}-$ open and $\tau_{\mathrm{G}}$-closed. The collection of all open neighborhoods of a point $\mathrm{x}$ in $(\mathrm{X}, \tau)$ will be denoted by $\tau(\mathrm{x})$.

$(X, \tau, G)$ denotes a topological space $(X, \tau)$ with a grill $G$.

Definition 2.2: Let $(X, \tau)$ be a topological space. A subset $A$ of $X$ is said to be

(1) semiclosed if int $\operatorname{cl}(\mathrm{A}) \subseteq \mathrm{A}$

(2) generalized closed (g closed) of $\mathrm{cl}(\mathrm{A}) \subseteq \mathrm{U}$ whenever $\mathrm{A} \subseteq \mathrm{U}$ and $\mathrm{U}$ is open in $\mathrm{X}$.

(3) generalized semi closed (gs closed) of scl $\mathrm{A} \subseteq \mathrm{U}$ whenever $\mathrm{A} \subseteq \mathrm{U}$ and $\mathrm{U}$ is open in $\mathrm{X}$.

(4) $\theta$-closed if $\mathrm{A}=\theta \mathrm{cl}$ A where

(5) $\delta$-closed if $\mathrm{A}=\delta \mathrm{cl} \mathrm{A}$ where

$$
\theta \mathrm{cl} \mathrm{A}=\{\mathrm{x} \in \mathrm{X}: \operatorname{cl}(\mathrm{U}) \cap \mathrm{A} \neq \phi, \forall \mathrm{U} \in \tau \text { and } \mathrm{x} \in \mathrm{U}\}
$$

$$
\delta \mathrm{cl} \mathrm{A}=\{\mathrm{x} \in \mathrm{X} ; \text { int } \mathrm{cl}(\mathrm{U}) \cap \mathrm{A} \neq \phi, \forall \mathrm{U} \in \tau \text { and } \mathrm{x} \in \mathrm{U}\}
$$

The complements of the above closed sets are respective open sets.

Definition 2.3: A function $f:(\mathrm{X}, \tau) \rightarrow(\mathrm{Y}, \sigma)$ is said to be

(1) gs continuous if $f^{-1}(\mathrm{U})$ is gs open in $\mathrm{X}$, for every open set $\mathrm{U}$ of $\mathrm{Y}$.

(2) $\theta$ continuous if $f^{-1}(U)$ is $\theta$ open in $X$, for every open set $U$ of $Y$.

(3) $\delta$-continuous if $f^{-1}(\mathrm{U})$ is $\delta$-open in $\mathrm{X}$ for every open set $\mathrm{U}$ of $\mathrm{Y}$.

Definition 2.4: A function $f:(\mathrm{X}, \tau) \rightarrow(\mathrm{Y}, \sigma)$ is said to be

(1) $(\mathrm{gs})^{*}$ closed if $f(\mathrm{~F})$ is $(\mathrm{gs}) *$ closed in $\mathrm{Y}$, for every closed set $\mathrm{F}$ of $\mathrm{X}$,

(2) $\tau_{\mathrm{G}}$ closed if $f(\mathrm{~F})$ is $\tau_{\mathrm{G}}$ closed in $\mathrm{Y}$, for every closed set $\mathrm{F}$ of $\mathrm{X}$.

(3) $\theta$ closed if $f(F)$ is $\theta$ closed in $Y$, for every closed set $F$ of $X$.

(4) $\delta$ closed if $f(\mathrm{~F})$ is $\delta$ closed in Y, for every closed set $\mathrm{F}$ of $\mathrm{X}$.

Theorem 2.5: [7] Let $(X, \tau)$ be a topological space and $G$ be a grill on $X$. Then for any $A, B \subseteq X$

\section{following hold}

$$
\begin{array}{ll}
\text { (a) } & \mathrm{A} \subseteq \mathrm{B} \Rightarrow \phi(\mathrm{A}) \subseteq \phi(\mathrm{B}) \\
\text { (b) } & \phi(\mathrm{A} \cup \mathrm{B})=\phi(\mathrm{A}) \cup \phi(\mathrm{B}) \\
\text { (c) } & \phi(\phi(\mathrm{A}) \subseteq \phi(\mathrm{A})=\mathrm{cl}(\phi(\mathrm{A})) \subseteq \mathrm{cl}(\mathrm{A})
\end{array}
$$




\section{G(gs)* CLOSED SETS}

Definition 3.1: A subset A of a topological space $(X, \tau)$ is said to be $(\mathrm{gs}) *$ closed set if $\operatorname{cl}(\mathrm{A}) \subseteq \mathrm{U}$ whenever $\mathrm{A} \subseteq \mathrm{U}$ and $\mathrm{U}$ is gs open in $\mathrm{X}$.

Definition 3.2: Let $(X, \tau)$ be a topological space and $G$ be a grill on $X$. Then the subset $A$ of $(X, \tau)$ is said to be $(g s)^{*}$ closed with respect to a grill $\mathrm{G}\left(\mathrm{G}(\mathrm{gs})^{*}\right.$ closed $)$ if $\phi(\mathrm{A}) \subseteq \mathrm{U}$ whenever $\mathrm{A} \subseteq \mathrm{U}$ and $\mathrm{U}$ gs open in $\mathrm{X}$.

The complement of $\mathrm{G}(\mathrm{gs}) *$ closed set in $\mathrm{X}$ is called $\mathrm{G}(\mathrm{gs})^{*}$ open in $\mathrm{X}$.

Theorem 3.3: Let $(X, \tau)$ be a topological space and $G$ be a grill on $X$. Then

(1) Every closed set in $\mathrm{X}$ in $\mathrm{G}(\mathrm{gs}) *$ closed

(2) For $A, G(g s)^{*}$ closed in $X, \phi(A)$ is $G(g s) *$ closed.

(3) Every $\tau_{\mathrm{G}}$ closed set is $\mathrm{G}(\mathrm{gs})^{*}$ closed.

(4) Any non-member of $\mathrm{G}$ is $\mathrm{G}(\mathrm{gs})^{*}$ closed.

(5) Any (gs)* closed set is $\mathrm{G}(\mathrm{gs})^{*}$ closed.

(6) Every $\theta$ closed set is $\mathrm{G}(\mathrm{gs}) *$ closed.

(7) Every $\delta$ closed set is $\mathrm{G}(\mathrm{gs}) *$ closed

\section{Proof:}

(1) Let $\mathrm{A}$ be closed. Then $\mathrm{cl}(\mathrm{A})=\mathrm{A}$. Let $\mathrm{A} \subseteq \mathrm{U}$ where $\mathrm{U}$ is gs open.

$\phi(\mathrm{A}) \subseteq \mathrm{cl} \mathrm{A}=\mathrm{A} \subseteq \mathrm{U}$. A is $\left.\mathrm{G}_{(\mathrm{gs})}\right)^{*}$ closed.

(2) $\mathrm{A}$ is $\mathrm{G}(\mathrm{gs}) *$ closed closed. $\phi(\mathrm{A}) \subseteq \mathrm{U}, \mathrm{U}$ is gs open. $\phi(\phi(\mathrm{A})) \subseteq \phi(\mathrm{A}) \subseteq \mathrm{U}$. Hence $\phi(\mathrm{A})$ is $\mathrm{G}(\mathrm{gs})^{*}$

(3) Let $\mathrm{A}$ be $\tau_{\mathrm{G}}$ closed. Let $\mathrm{A} \subseteq \mathrm{U}$, where $\mathrm{U}$ is gs open. As $\mathrm{A}$ is $\tau_{\mathrm{G}}$ closed, $\phi(\mathrm{A}) \subseteq \mathrm{A} \subseteq \mathrm{U}$. Hence $\mathrm{A}$ is $\mathrm{G}(\mathrm{gs})$ * closed.

(4) Let $A \notin G$. Let $A \subseteq U, U$ is gs open. $\phi(A)=\phi \subseteq U$. Hence $A$ is $G(g s)^{*}$ closed.

(5) Let $\mathrm{A} \subseteq \mathrm{U}$, $\mathrm{U}$ is gs open. $\mathrm{A}$ is $(\mathrm{gs})^{*}$ closed. Hence $\mathrm{cl} \mathrm{A} \subseteq \mathrm{U}$. So $\phi(\mathrm{A}) \subseteq \mathrm{cl} \mathrm{A} \subseteq \mathrm{U}$. Therefore $\mathrm{A}$ is $\mathrm{G}(\mathrm{gs})^{*}$ closed.

(6) Let $\mathrm{A} \subseteq \mathrm{U}, \mathrm{U}$ is gs open. $\mathrm{A}$ is $\theta$ closed $\phi(\mathrm{A}) \subseteq \mathrm{cl} \mathrm{A} \subseteq \theta \subseteq \mathrm{cl}(\mathrm{A})=\mathrm{A} \subseteq \mathrm{U}$. Hence $\mathrm{A}$ is $\mathrm{G}(\mathrm{gs})^{*}$ closed.

(7) Let $\mathrm{A} \subseteq \mathrm{U}, \mathrm{U}$ is gs open $\mathrm{A}$ is $\delta \operatorname{closed} \phi(\mathrm{A}) \subseteq \mathrm{cl} \mathrm{A} \subseteq \delta \mathrm{cl} \mathrm{A}=\mathrm{A} \subseteq \mathrm{U}$. Hence $\mathrm{A}$ is $\mathrm{G}(\mathrm{gs})^{*}$ closed. The converse of the above statements need not be true can be seen from the following examples.

Example 3.4: Let $X=\{a, b, c\}$

$\tau=\{\phi,\{a\},\{a, b\}, X\}$

$\mathrm{G}=\{\{\mathrm{a}\},\{\mathrm{a}, \mathrm{b}\},\{\mathrm{a}, \mathrm{c}\}, \mathrm{X}\}, \mathrm{A}=\{\mathrm{b}\}$. Let $\mathrm{A} \subseteq \mathrm{U}$ where $\mathrm{U}$ is gs open.

$\phi(\mathrm{A})=\phi \subseteq \mathrm{U}$. Hence $\mathrm{A}$ is $\mathrm{G}(\mathrm{gs})^{*}$ closed but not $\mathrm{A}=\{\mathrm{b}\}$ is closed.

Example 3.5: Let $X=\{a, b, c\}$,

$\tau=\{\phi,\{a\}, X\}, G=\{\{a\},\{a, b\},\{a, c\}, X\}$

$\mathrm{A}=\{\mathrm{a}\}, \phi(\mathrm{A})=\{\mathrm{a}, \mathrm{b}, \mathrm{c}\} \not\{\mathrm{a}\}$.

A is not $\mathrm{G}_{(\mathrm{gs})}$ * closed. $\phi(\mathrm{A})$ is $\mathrm{G}_{(\mathrm{gs})}$ * closed.

Example 3.6: Let $X=\{a, b, c\}$,

$\tau=\{\phi,\{a, b\}, X\}$

$\mathrm{G}=\{\{a\},\{b\},\{c\},\{a, b\},\{a, c\},\{b, c\}, X\}$

$\mathrm{A}=\{\mathrm{b}, \mathrm{c}\} \mathrm{A}$ is $\mathrm{G}(\mathrm{gs}) *$ closed but not $\tau_{\mathrm{G}}$ closed.

Example 3.7: Refer example 3.6

$\mathrm{A}$ is $\mathrm{G}(\mathrm{gs}) *$ closed but not a nonmember.

Example 3.8: Refer example 3.5 Let $G=\{\{b, c\}, X\}$

A is $\mathrm{G}(\mathrm{gs}) *$ closed but not $(\mathrm{gs}) *$ closed.

Example 3.9: Refer example 3.5

A is $\mathrm{G}(\mathrm{gs}) *$ closed but not $\square$ closed.

Example 3.10: Refer example 3.5

A is $\mathrm{G}(\mathrm{gs})^{*}$ closed but not $\delta$ closed.

Lemma 3.11 : Let $(\mathrm{X}, \tau)$ be a space and $\mathrm{G}$ be a grill on $\mathrm{X}$. If $\mathrm{A} \subseteq \mathrm{X}$ is $\tau_{\mathrm{G}}-$ dense in itself, then

$\phi(\mathrm{A})=\operatorname{cl} \phi(\mathrm{A})=\tau_{\mathrm{G}}-\operatorname{cl}(\mathrm{A})=\operatorname{cl}(\mathrm{A})$ 
Theorem 3.12: Let $(X, \tau)$ be topological space and $G$ be a grill on $X$. Then for $A \subseteq X, A$ is $G(g s)^{*}$ closed iff $\tau_{\mathrm{G}}$ $-\operatorname{cl}(\mathrm{A}) \subseteq \mathrm{U}, \mathrm{A} \subseteq \mathrm{U}$ and $\mathrm{U}$ is gs open.

Proof: Suppose $\mathrm{A}$ is $\mathrm{G}(\mathrm{gs})^{*}$ closed. Then $\phi(\mathrm{A}) \subseteq \mathrm{U} \Rightarrow \mathrm{A} \cup \phi(\mathrm{A}) \subseteq \mathrm{U}$. Therefore, $\tau_{\mathrm{G}}-\operatorname{cl}(\mathrm{A}) \subseteq \mathrm{U}, \mathrm{A} \subseteq \mathrm{U}$ and $\mathrm{U}$ is gs open.

Conversely $\tau_{\mathrm{G}}-\operatorname{cl}(\mathrm{A}) \subseteq \mathrm{U}, \mathrm{A} \subseteq \mathrm{U}, \mathrm{U}$ is gs open

Therefore $\mathrm{A} \cup \phi(\mathrm{A}) \subseteq \mathrm{U} \Rightarrow \phi(\mathrm{A}) \subseteq \mathrm{U}$. Hence $\mathrm{A}$ is $\mathrm{G}(\mathrm{gs}) *$ closed.

Theorem 3.13: Let $G$ be a grill on a space $(X, \tau)$. If $A$ is $\tau_{G}$-dense in itself and $G(g s)^{*}$ closed implies $A$ is (gs)* closed.

Proof: Let $\mathrm{A}$ be $\tau_{\mathrm{G}}$-dense in itself, then by lemma 3.1, $\phi(\mathrm{A})=\operatorname{cl}(\mathrm{A})$.

Since $\mathrm{A}$ is $\mathrm{G}(\mathrm{gs})$ * closed, $\phi(\mathrm{A}) \subseteq \mathrm{U}$ where $\mathrm{U}$ is gs open in $\mathrm{X}$ and $\mathrm{A} \subseteq \mathrm{U}$.

Therefore $\mathrm{cl}(\mathrm{A}) \subseteq \mathrm{U}$ where $\mathrm{U}$ is gs open in $\mathrm{X}$ and $\mathrm{A} \subseteq \mathrm{U}$. Hence $\mathrm{A}$ is $(\mathrm{gs}) *$ closed.

Theorem 3.14: For any grill $G$ ona space $(X, \tau)$ the following are equivalent.

(a) Every subset of $\mathrm{X}$ is $\mathrm{G}(\mathrm{gs})$ * closed.

(b) Every gs open subset of $(\mathrm{X}, \tau)$ is $\tau_{\mathrm{G}}$-closed.

Proof: (a) $\Rightarrow$ (b)

Let $\mathrm{A}$ be $\mathrm{gs}$ open in $(\mathrm{X}, \tau)$. Then by $(\mathrm{a}), \mathrm{A}$ is $\mathrm{G}(\mathrm{gs}) *$ closed, so that $\phi(\mathrm{A}) \subseteq \mathrm{A}$. Therefore $\mathrm{A}$ is $\tau_{\mathrm{G}}$-closed.

(b) $\Rightarrow(\mathrm{a})$. Let $\mathrm{A} \subseteq \mathrm{X}$ and $\mathrm{U}$ be gs open in $(\mathrm{X}, \tau)$ such that $\mathrm{A} \subseteq \mathrm{U}$. Then $(\mathrm{b}), \phi(\mathrm{U}) \subseteq \mathrm{U}$.

Also, $\mathrm{A} \subseteq \mathrm{U} \Rightarrow \phi(\mathrm{A}) \subseteq \phi(\mathrm{U}) \subseteq \mathrm{U}$

There $A$ is $G(g s) *$ closed.

Theorem 3.15: Let $(X, \tau)$ be a topological space and $G$ be a grill on $X$ and $A, B$ be subsets of $X$ such that $\mathrm{A} \subseteq \mathrm{B} \subseteq \tau_{\mathrm{G}}-\mathrm{cl}(\mathrm{A})$. If $\mathrm{A}$ is $\mathrm{G}(\mathrm{gs}) *$ closed then $\mathrm{B}$ is $\mathrm{G}(\mathrm{gs}) *$ closed.

Proof: Suppose $B \subseteq U$ and $U$ is gs open in $X$. Since $A$ is $G(g s)^{*}$ closed.

$\phi(\mathrm{A}) \subseteq \mathrm{U} \Rightarrow \tau \mathrm{G}-\mathrm{cl}(\mathrm{A}) \subseteq \mathrm{U} \ldots(1)$

Now, $\mathrm{A} \subseteq \mathrm{B} \subseteq \tau \mathrm{G}-\mathrm{cl}(\mathrm{A})$ which implies $\tau_{\mathrm{G}}-\mathrm{cl}(\mathrm{A}) \subseteq \tau_{\mathrm{G}}-\mathrm{cl}(\mathrm{B}) \subseteq \tau_{\mathrm{G}}-\mathrm{cl}(\mathrm{A})$.

Therefore $\tau_{\mathrm{G}}-\operatorname{cl}(\mathrm{A})=\tau_{\mathrm{G}}-\operatorname{cl}(\mathrm{B})$

Therefore by (1) $\tau_{\mathrm{G}}-\mathrm{cl}(\mathrm{B}) \subseteq \mathrm{U}$. Hence $\mathrm{B}$ is $\mathrm{G}(\mathrm{gs})^{*}$ closed.

Corollary 3.16: $\tau_{\mathrm{G}}$-closure of every $\mathrm{G}(\mathrm{gs}) *$ closed set is $\mathrm{G}(\mathrm{gs}) *$ closed.

Theorem 3.17: Let $G$ be a grill on a space $(X, \tau)$ and $A, B$ be subsets of $X$ such that $A \subseteq B \subseteq \phi(A)$. If $A$ is $G(g s)^{*}$ closed then $\mathrm{A}$ and $\mathrm{B}$ are gs closed.

Proof: Let $\mathrm{A} \subseteq \mathrm{B} \subseteq \phi(\mathrm{A})$, then $\mathrm{A} \subseteq \mathrm{B} \subseteq \tau \mathrm{G}-\operatorname{cl}(\mathrm{A})$. By theorem 3.15, $\mathrm{B}$ is $\mathrm{G}(\mathrm{gs})^{*}$ closed. Again $\mathrm{A} \subseteq \mathrm{B} \subseteq$ $\phi(\mathrm{A}) \Rightarrow \phi(\mathrm{A}) \subseteq \phi(\mathrm{B}) \subseteq \phi(\phi(\mathrm{A})) \subseteq \phi(\mathrm{A})$. This implies that $\phi(\mathrm{A})=\phi(\mathrm{B})$. By theorem 3.13, A and B are gs closed.

Theorem 3.18: Let $G$ be a Grill on a space $(X, \tau)$. Then a subset $A$ of $X$ is $G(g s) *$ open iff $F \subseteq \tau_{G}-$ int $(A)$ whenever $\mathrm{F} \subseteq \mathrm{A}$ and $\mathrm{F}$ is gs closed.

Proof: Let $A$ be $\mathrm{G}(\mathrm{gs})^{*}$ open set and $\mathrm{F} \subseteq \mathrm{A}$ where $\mathrm{F}$ is gs closed. Then $\mathrm{X} \backslash \mathrm{A} \subseteq \mathrm{X} \backslash \mathrm{F}$. This implies that $\phi(\mathrm{X} \backslash \mathrm{A}) \subseteq \phi(\mathrm{X} \backslash \mathrm{F})=\mathrm{X} \backslash \mathrm{F}$. Hence $\tau_{\mathrm{G}}-\mathrm{cl}(\mathrm{X} \backslash \mathrm{A}) \subseteq \mathrm{X} \backslash \mathrm{F}$ which implies $\mathrm{F} \subseteq \tau_{\mathrm{G}}-$ int $(\mathrm{A})$

Conversely, $\mathrm{F} \subseteq \tau \mathrm{G}-(\operatorname{int}(\mathrm{A})), \tau \mathrm{G} \operatorname{cl}(\mathrm{X}-\mathrm{A}) \subseteq \mathrm{X}-\mathrm{F}, \phi(\mathrm{X}-\mathrm{A}) \subseteq \mathrm{X}-\mathrm{F}, \mathrm{A}$ is $\mathrm{G}(\mathrm{gs}) *$ open.

Remark 3.19:

(a) Every continuous function is gs continuous.

(b) Every gs - continuous function is $\mathrm{G}(\mathrm{gs}) *$ continuous.

Example 3.20: Refer example 3.5

Define $f:(X, \tau, G) \rightarrow(X, \tau)$ by $f(a)=c, f(b)=a, f(c)=b f$ is gs continuous but not continuous as $f^{-1}(\{a\})=\{b\}$ is not open. Define $\mathrm{f}$ by $\mathrm{f}(\mathrm{a})=\mathrm{c}, \mathrm{f}(\mathrm{b})=\mathrm{a}, \mathrm{f}(\mathrm{c})=\mathrm{a}, \mathrm{f}$ is $\mathrm{G}(\mathrm{gs})^{*}$ continuous but not gs continuous as $\mathrm{f}^{-1}(\{\mathrm{a}\})=\{\mathrm{b}, \mathrm{c}\}$ is not $g s$ open.

Remark 3.21: Every $\square$-continuous function is $\mathrm{G}(\mathrm{gs}) *$ continuous.

Example 3.22: Refer example 3.5

Define $f:(\mathrm{X}, \tau, \mathrm{G}) \rightarrow(\mathrm{X}, \tau)$ by $f(\mathrm{a})=\mathrm{c}, f(\mathrm{~b})=\mathrm{a}, f(\mathrm{c})=\mathrm{a} . f$ is $\mathrm{G}(\mathrm{gs})$ * continuous but not $\square$ continuous as $f^{-1}(\{\mathrm{a}\})=\{\mathrm{b}, \mathrm{c}\}$ is not $\square$ open.

Remark 3.23: Every $\delta$-continuous function is $\mathrm{G}(\mathrm{gs}) *$ continuous.

Example 3.24: Refer example 3.22 
$f$ is $\mathrm{G}(\mathrm{gs}) *$ continuous but not $\delta$ continuous as $f^{-1}(\{\mathrm{a}\})=\{\mathrm{b}, \mathrm{c}\}$ is not $\delta$ open.

Definition 3.25: $\tau_{\mathrm{G}}$, (gs)* closed function.

A function $f:(\mathrm{X}, \tau) \square(\mathrm{Y}, \tau, \mathrm{G})$ is said to be $\tau_{\mathrm{G}}(\mathrm{gs}) *$ closed if $f(\mathrm{~A})$ is $\tau_{\mathrm{G}}(\mathrm{gs}) *$ closed in $\mathrm{Y}$ for every closed set $\mathrm{A}$ in X.

Definition 3.26: A function $f:(\mathrm{X}, \tau) \square(\mathrm{Y}, \tau, \mathrm{G})$ is said to be $\square \square$ closed if $f(\mathrm{~A})$ is $\square$ closed in $\mathrm{Y}$ for every closed set A in X.

Definition 3.27: A function $f:(\mathrm{X}, \tau) \square(\mathrm{Y}, \tau, \mathrm{G})$ is said to be $\delta$ closed if $f(\mathrm{~A})$ is $\delta$ closed in $\mathrm{Y}$ for every closed set $\mathrm{A}$ in $X$.

Definition 3.28: A function $f:(\mathrm{X}, \tau) \square(\mathrm{Y}, \tau, \mathrm{G})$ is said to be $\phi\left(\mathrm{G}(\mathrm{gs})^{*}\right)$ closed if $f(\mathrm{~A})$ is $\phi\left(\mathrm{G}(\mathrm{gs})^{*}\right)$ closed in $\mathrm{Y}$ for every closed set $\mathrm{A}$ in $\mathrm{X}$.

\section{Theorem 3.29:}

1. Every closed function is $\mathrm{G}(\mathrm{gs})^{*}$ closed function.

2. Every $G(g s) *$ closed function is $\phi(G(g s) *)$ closed function.

3. Every $\tau_{\mathrm{G}}$ closed function is $\mathrm{G}(\mathrm{gs})^{*}$ closed function.

4. Every $(\mathrm{gs}) *$ closed function is $\mathrm{G}(\mathrm{gs}) *$ closed function.

5. Every $\square$ closed function is $\mathrm{G}(\mathrm{gs})^{*}$ closed function.

6. Every $\delta$ closed function is $\mathrm{G}(\mathrm{gs}) *$ closed function.

Proof: Obvious

The converse of the above statements need not be true can be seen from the following examples.

Example 3.30: Refer example 3.4

Define $f:(\mathrm{X}, \tau) \square(\mathrm{X}, \tau, \mathrm{G})$ by $\mathrm{f}(\mathrm{a})=\mathrm{a}, \mathrm{f}(\mathrm{b})=\mathrm{c}, \mathrm{f}(\mathrm{c})=\mathrm{b}$. $\mathrm{f}$ is $\mathrm{G}(\mathrm{gs}) *$ closed but not closed as $f(\{\mathrm{c}\})=\{\mathrm{b}\}$ is not closed in $\mathrm{X}$.

Example 3.31: Refer example 3.4

Define $f:(\mathrm{X}, \tau) \square(\mathrm{X}, \tau, \mathrm{G})$ by $\mathrm{f}(\mathrm{a})=\mathrm{a}, \mathrm{f}(\mathrm{b})=\mathrm{c}, \mathrm{f}(\mathrm{c})=\mathrm{b}$. $\mathrm{f}$ is $\phi \mathrm{G}(\mathrm{gs})^{*}$ closed function but not $\mathrm{G}(\mathrm{gs}) *$ closed function as $f(\{\mathrm{c}\})=\{\mathrm{a}\}$ is not $\mathrm{G}(\mathrm{gs}) *$ closed.

Example 3.32: Refer example 3.6

Let $\mathrm{f}:(\mathrm{X}, \tau) \square(\mathrm{X}, \tau, \mathrm{G})$ be the identity function $\mathrm{f}$ is $\mathrm{G}(\mathrm{gs})^{*}$ closed function but not $\tau \mathrm{G}$ closed function as $\mathrm{f}(\{\mathrm{b}, \mathrm{c}\})=\{\mathrm{b}$, c) is not $\tau \mathrm{G}$ closed.

Example 3.33: Refer example 3.6

Define $f:(\mathrm{X}, \tau) \square(\mathrm{X}, \tau, \mathrm{G})$ by $f(\mathrm{a})=\mathrm{b}, f(\mathrm{~b})=\mathrm{a}, f(\mathrm{c})=\mathrm{a} . f$ is $\mathrm{G}(\mathrm{gs})^{*}$ closed function but not (gs)* closed function.

Example 3.34: Refer example 3.6

Define $f:(\mathrm{X}, \tau) \square(\mathrm{X}, \tau, \mathrm{G})$ by $f(\mathrm{a})=\mathrm{b}, f(\mathrm{~b})=\mathrm{a}, f(\mathrm{c})=\mathrm{a} . f \mathrm{is} \mathrm{G}(\mathrm{gs})^{*}$ closed function but not (gs)* a closed function as $f(\{\mathrm{~b}, \mathrm{c}\})=\{\mathrm{a}\}$ is not $(\mathrm{gs}) *$ closed.

Example 3.35: Refer the previous example, $f$ is $\mathrm{G}(\mathrm{gs})^{*}$ closed function but not $\square$ closed function as $f(\{\mathrm{~b}, \mathrm{c}\})=\{\mathrm{a}\}$ is not $\square$ closed.

Example 3.36: Refer the previous example, $f$ is $\mathrm{G}(\mathrm{gs})^{*}$ closed function but not $\delta$ closed function as $f(\{b, c\})=\{a\}$ is not $\delta$ closed.

Theorem 3.37: If $\mathrm{f}:(\mathrm{X}, \tau) \theta(\mathrm{Y}, \sigma)$ is closed and $\mathrm{g}:(\mathrm{Y}, \sigma) \theta(\mathrm{Z}, \eta, \mathrm{G})$ is $\mathrm{G}(\mathrm{gs})^{*}$ closed then $(\mathrm{Z}, \eta, \mathrm{G})$ is $\mathrm{G}(\mathrm{gs}) *$ is closed.

$\mathrm{g}$ of : $(\mathrm{X}, \tau) \theta$

Theorem 3.38: A map $f: \mathrm{X} \square \mathrm{Y}$ is $\mathrm{G}(\mathrm{gs})^{*}$ closed if and only if for each subset $\mathrm{S}$ of $\mathrm{Y}$ and each open set $\mathrm{U}$ of $\mathrm{X}$ such that $f^{-1}(\mathrm{~S}) \subseteq \mathrm{U}$, there is a $\mathrm{G}(\mathrm{gs})^{*}$ open subset $\mathrm{V}$ of $\mathrm{Y}$ such that $\mathrm{S} \subset \mathrm{V}$ and $f^{-1}(\mathrm{~V}) \subseteq \mathrm{U}$.

Proof: Let $f$ be $\mathrm{G}(\mathrm{gs})^{*}$ closed. Let $\mathrm{S} \subseteq \mathrm{Y}$ and $\mathrm{U}$ be an open set of $\mathrm{X}$ such that $f^{-1}(\mathrm{~S}) \subseteq \mathrm{U}$. X $-\mathrm{U}$ is closed in $\mathrm{X} . f(\mathrm{X}-\mathrm{U})$ is $\mathrm{G}(\mathrm{gs})^{*}$ closed in $\mathrm{Y} . \mathrm{V}=\mathrm{Y}-f(\mathrm{X}-\mathrm{U})$ is $\mathrm{G}(\mathrm{gs}) *$ open in $\mathrm{Y}$.

$f^{-1}(\mathrm{~V})=\mathrm{X}-f^{-1}(f(\mathrm{X}-\mathrm{U})) \subseteq \mathrm{X}-(\mathrm{X}-\mathrm{U})=\mathrm{U}$

Conversely, let $\mathrm{F}$ be closed in $\mathrm{X} . f^{-1}\left(f\left(\mathrm{~F}^{\mathrm{c}}\right)\right) \subseteq \mathrm{F}^{\mathrm{c}}$ and $\mathrm{F}^{\mathrm{c}}$ is open in $\mathrm{X}$.

By assumption, there exists a $\mathrm{G}(\mathrm{gs}) *$ open subset $\mathrm{V}$ of $\mathrm{Y}$ such that $f\left(\mathrm{~F}^{\mathrm{c}}\right) \subset \mathrm{V}$ and $f^{-1}(\mathrm{v}) \subseteq \mathrm{F}^{\mathrm{c}}$. This implies $\mathrm{F}$ 
$\subseteq\left(f^{-1}(\mathrm{~V})\right)^{\mathrm{c}}$

Hence $\mathrm{V}^{\mathrm{c}} \subseteq\left(f\left(\mathrm{~F}^{\mathrm{c}}\right)\right)^{\mathrm{c}}=f(\mathrm{~F}) \subseteq f\left(f^{-1}(\mathrm{~V})\right)^{\mathrm{c}} \subseteq \mathrm{V}^{\mathrm{c}}$

So, $f(\mathrm{~F})=\mathrm{V}^{\mathrm{c}}$, which is $\mathrm{G}(\mathrm{gs})^{*}$ closed.

Definition 3.39: Let $\mathrm{X}$ and $\mathrm{Y}$ be topological spaces. A map $f: \mathrm{X} \square \mathrm{Y}$ is called $\mathrm{G}(\mathrm{gs})^{*}$ open map if the image of every open set of $\mathrm{x}$ is $\mathrm{G}(\mathrm{gs})^{*}$ open in $\mathrm{Y}$.

Theorem 3.40: For any bijection map $f: \mathrm{X} \square \mathrm{Y}$, the following are equivalent.

(1) $f^{-1}: \mathrm{Y} \square \mathrm{X}$ is $\mathrm{G}(\mathrm{gs})^{*}$ continuous map

(2) $f$ is $\mathrm{G}(\mathrm{gs})^{*}$ open map

(3) $f$ is $\mathrm{G}(\mathrm{gs}) *$ closed map

Proof: $(1) \Rightarrow(2)$ :

Let $\mathrm{U}$ be open in $\mathrm{X}\left(f^{-1}\right)^{-1}(\mathrm{U})$ is $\mathrm{G}(\mathrm{gs})^{*}$ open in $\mathrm{Y}$. That is $f(\mathrm{U})$ is $\mathrm{G}(\mathrm{gs})^{*}$ open in $\mathrm{Y}$.

(2) $\Rightarrow(3)$ :

Let $\mathrm{F}$ be a closed set of $\mathrm{X}$. Then $\mathrm{F}^{\mathrm{c}}$ is open in $\mathrm{X}$.

By assumption

$f\left(\mathrm{~F}^{\mathrm{c}}\right)$ is $\mathrm{G}(\mathrm{gs})^{*}$ open in $\mathrm{Y} \cdot f\left(\mathrm{~F}^{\mathrm{c}}\right)=(f(\mathrm{~F}))^{\mathrm{c}}$ is $\mathrm{G}(\mathrm{gs})^{*}$ open in $\mathrm{Y}$.

$f(\mathrm{~F})$ is $\mathrm{G}(\mathrm{gs})^{*}$ closed in $\mathrm{Y}$.

(3) $\Rightarrow(1)$ :

Let $\mathrm{F}$ be closed in X. $f(\mathrm{~F})$ is $\mathrm{G}(\mathrm{gs})^{*}$ closed in Y. $f(\mathrm{~F})=\left(f^{-1}\right)^{-1}(\mathrm{~F})$ is $\mathrm{G}(\mathrm{gs})^{*}$ closed in Y. Hence $f^{-1}$ is $\mathrm{G}(\mathrm{gs})^{*}$ continuous map.

\section{References:}

[1]. G Choquet, "Sur les notions de filter et grille", comptesRendus Acad. Sci. Paris, 224(1947), 171-173.

[2]. DhananjoyMandal and M.N. Mukherjee, "On a type of generalized closed sets", Bol. Soc. Paran. Mat. 301 (2012), 67-76.

[3]. J. Dontchev and T.Noiri, "Quasi Normal spaces and $\square$ g-closed sets”, Acta. Math. Hunger, 89(3) (2000), 211219.

[4]. J. Dontchev and H. Maki, “On $\square$-generalized closed sets", Topology Atlass.

[5]. S. Fomin, "Extensions of topological spaces", Ann. Math, 44 (1943), 471-480.

[6]. N. Levine, "Generalized closed sets in topology", Rend. cire. Mat, Palermo, (2), 19(1970), 89-96.

[7]. B. Roy and M.N. Mukherjee, "On a typical topology induced by a grill", Sooochow J. Math, 33(4) (2007), 771786.

[8]. M.H. Stone, "Application of the theory of Boolean rings to general topology", Trans, Amer, Math. Soc., 41 (1937), 374-481.

[9]. M.K.R.S. Veerakumar, "Between closed and $g$ closed sets," Mem. Fac. Sci Kochi. Univer. Math vol 21(2000), $1-19$. 